\title{
Ethinyl Estradiol/Norethindrone
}

\author{
National Cancer Institute
}

\section{Source}

National Cancer Institute. Ethinyl Estradiol/Norethindrone. NCI Thesaurus. Code C29035.

An oral contraceptive formulation containing the semisynthetic estrogen, ethinyl estradiol, combined with the synthetic progestin, norethindrone, with estrogenic and progestogenic activities, respectively. Ethinyl estradiol binds to and activates intracellular estrogen receptors found in the reproductive tract and other estrogen-responsive tissues. The activated complex enters the nucleus, binds to the estrogen response elements on DNA, activates the transcription of genes involved in the maintenance of the female reproductive system, inhibits the release of follicle stimulating hormone (FSH) from the anterior pituitary, and suppresses the development of the ovarian follicle. Norethindrone binds to intracellular progesterone receptors in progesterone-responsive tissues, such as the pituitary and those found in the reproductive system, and the activated ligand/receptor complex interacts with specific progesterone response elements on DNA, which results in the alteration in protein synthesis, the inhibition of ovulation, an increase in cervical mucus production, the induction of the secretory phase of the endometrial cycle, and the inhibition of luteinizing hormone (LH) release. The combination of an estrogen with a progestin suppresses the hypothalamic-pituitary system and alters the structure of the endometrium to discourage implantation. 